\title{
Contribution to the Methodology for the Selection of Technologically Most Appropriate Variant of the Water Supply System by Using Promethee
}

\author{
Bojan Đurin, Lucija Nađ \\ University of Zagreb, Varaždin, Croatia
}

\begin{abstract}
Water supply systems and their complexity demands analysis of a lot of different variants of obtained solutions for different types of water supply systems. Nowadays, in addition to meeting the technological and economic criteria, it is necessary to meet other criteria, such as environmental, social, law and many others. Among other procedures, multi-criteria methods are very often used for the solution of such issues. This paper will present the use of the multi-criteria method Promethee for the application of technological criteria. The purpose of this is finding a technologically most appropriate variant of the observed water supply system, given that the resulting solution variants differ according to the input parameters and size of certain parts. In addition, this paper explains the scientifically innovative and, in view of engineering, applicable methodology (Critical Period Method) for sizing the sustainable urban water supply system driven by solar photovoltaic $(P V)$ energy.
\end{abstract}

\section{Introduction}

Rational and sustainable use of water and energy is one of most important tasks which have to be secured in every part of the world where people live. Also, satisfying of quality and quantity of water supply is of great importance for the quality of living of urban areas throughout the world. Political and legal provisions contained in a big number of laws, guidelines and accompanying regulations also contribute to such reasoning [1]. Urban water systems (UWS) i.e. are infrastructures which significantly reduce environmental health problems and thus contribute to the sustainability of cities and sustainable development in general.

Energy is necessary to bring water to the consumers. One characteristic of UWS is that water consumption goes hand in hand with energy consumption. Renewable energy, especially solar photovoltaic (PV) energy, which directly converts solar energy into electricity, offers a practical and sustainable solution to the challenge of meeting the increasing global energy demand. The Sun continuously provides the Earth with a huge amount of energy, equally distributed all over the world. It is clean, abundant, and a more and more economical

energy source. In this paper, interaction and interconnections between this kind of energy and water distribution will be described and explained.

\section{Main Concepts of the Analyzed Water Supply System}

The analyzed system consists of three main subsystems (parts), (see Figure 1) [2]. These are: solar photovoltaic (PV) generator and inverter with required equipment, - subsystem $\mathrm{PV}$, pumping station with required equipment - subsystem PS and reservoir - subsystem V, also with required equipment. These subsystems make up an integrated technological system and are functionally interconnected.

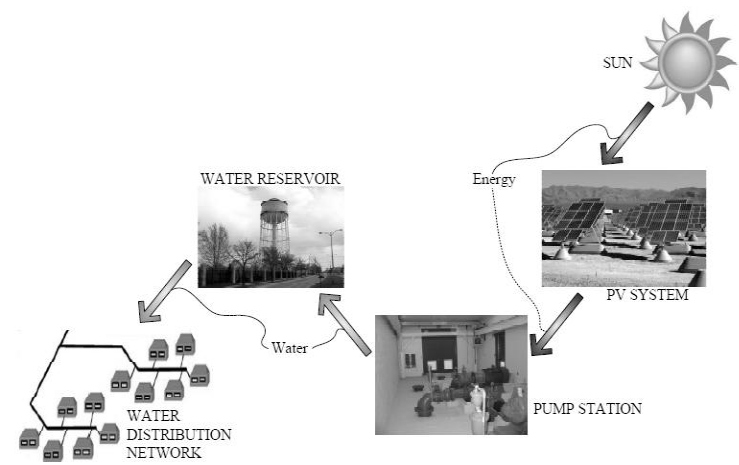

Figure 1. Urban Water Supply System (UWSS) driven by solar photovoltaic (PV) energy

This system basically turns solar energy from the Sun into direct electricity in the subsystem PV and after that, via invertor, into alternate electricity, which is used for pumping of water into the water reservoir. Solar energy is of stochastic nature in view of intensity and duration of solar radiation. Therefore, the role of water reservoir as a reservoir of water, i.e. energy, in conjunction with possible electric energy production from the subsystem PV, is crucial in providing the continuity and safety of water supply. In other words, the Urban Water Supply System (UWSS) must be appropriately and sized, i.e. the methodology described in this paper must be applied in order to realize Energy Sustainable Urban Water Supply System (ESUWSS). Given the scope and purpose of this 
study, the detailed procedures and terms for sizing individual parts of the system will not be explained, but they can be found in [3] and [4].

\section{Applied Methodology}

\subsection{Critical Period Method}

Novelty or the difference between the previous ways of dimensioning and dimensioning using the CPM is that instead of one critical period which relates to the maximum daily consumption of water, the CPM considers three critical periods. In the case of using PV energy for UWSS, these critical periods are: critical periods for sizing the subsystem PV (PV generator and inverter) $t_{P e l(i)}^{*}$, critical periods for sizing the subsystem PS (pumping station) $t_{P S(i)}^{*}$ and critical periods for sizing the subsystem $\mathrm{V}$ (water reservoir) $t_{V(i)}^{*}$ [4]. This provides security of the operation of each subsystem, since the sizing is performed with respect to the critical period(s) of each subsystem, which allows operating integrity of the entire ESUWSS.

The first critical period $t_{P e l(i)}^{*}$ is defined for determining sufficient power of subsystem PV $P_{e l, P V}$, which will provide enough electric energy for pumping water into the reservoir every day of the analyzed year, in accordance with the regime of daily water consumption in a settlement. This is the period (periods) in which the difference $\Delta V_{P e l(i)}$ between the daily required water for population needs $V_{\text {daily }(i)}$ and daily pumped water $V_{P S(i)}$ is minimum for every day of the year with regard to the balancing period $t_{b}$ :

$$
\begin{gathered}
\Delta V_{P e l, P V(i)}=V_{P S(i)}-V_{\text {daily }(i)}, \\
i=1,2, . ., 365 \Rightarrow \\
\min \Delta V_{P e l, P V(i)} \Rightarrow t_{P e l, P V(i)}^{*}
\end{gathered}
$$

where $\Delta V_{P e l, P V(i)}$ is acceptable difference in practical application, which is normally 0 .

The duration of daily solar radiation $T_{s(i)}$ determines the possible operating period of the pumping station. This introduces the second critical period (periods) $t_{P S(i)}^{*}$ for determining the capacity or power of the pumping station. $t_{P S(i)}^{*}$ is the critical period (periods) in which the relationship between the daily consumption of water in a settlement $V_{\text {daily (i) }}$ and duration of daily solar radiation $T_{s(i)}$ is minimum:

$$
\max Q_{d a i l y}=\frac{V_{d a i l y(i)}}{T_{s(i)}} \Rightarrow t_{P S(i)}^{*}
$$

It is understood that adequate PV subsystem power $P_{e l, P V}$ is provided, with respect to the corresponding critical period $t_{P e l(i)}^{*}$. Thus, in accordance with the rules of the profession, the capacity of the pumping station is determined that can pump the required quantity of water $Q_{\text {hour }(t)}$ $\left(\mathrm{m}^{3} / \mathrm{h}\right)$, which in fact represents the highest flow per hour during a typical year in the planning period.

The critical period (periods) $t_{V(i)}^{*}$ for determining the reservoir volume $V$ is the period in which maximum daily water consumption in a settlement $V_{\text {daily }(i)}$ for each day $i$ is maximum during the year, where the intensity of solar radiation $E_{s(i)}$ and its duration $T_{s(i)}$ is satisfactory, so that subsystem PV can produce sufficient electricity to drive the main pumping station. It is understood that adequate PV subsystem power $P_{e l, P V}$ is provided with respect to the corresponding critical period $t_{P e l(i)}^{*}$ and sufficient subsystem PS capacity $Q_{P S}$, also with respect to the corresponding critical period $t_{P S(i)}^{*}$ :

$$
\max V_{\text {daily }(i)} \Rightarrow t_{V(i)}^{*}
$$

Each of the three critical periods is determined with regard to a certain balancing period (periods) $t_{b}$, i.e. equalization periods of the required and pumped water or equalization periods of the required and produced energy. The shortest possible balancing period $t_{b}$ is one day. When the balancing period $t_{b}$ is longer the solution is in principle safer, because longer balancing period reduces the impact of extreme low insolation $E_{s}$ on the required power of the subsystem PV, $P_{e l, P V}$. In addition, the system is more efficient with regard to the possibility of using solar radiation, since the sum of the total available solar insolation is greater when $t_{b}$ is longer, because it eliminates the impact of extreme maximum individual daily duration and intensity of solar radiation. Therefore, the solution is safer and more rational in view of dimensioning the subsystem PV. This means that the required water can be pumped with a lower installed power of the subsystem PV.

\subsection{Promethee}

PROMETHEE is an outranking method for a finite set of alternative actions to be ranked and selected among criteria, which are often conflicting. 
PROMETHEE is also a quite simple ranking method in conception and application compared with the other methods for multi-criteria analysis [5]. Alternatives are evaluated according to different criteria, which have to be maximized or minimized. Determination of the weights is an important step in most multi-criteria methods. It is assumed that the decision-maker is able to weigh the criteria appropriately, at least when the number of criteria is not too large [6]. For each criterion, the preference function translates the difference between the evaluations obtained by two alternatives into a preference degree ranging from zero to one. The alternatives evaluated will be generated as a function of the balancing period length (number of days) $t_{b}$.

\section{Case Study}

This paper presents a hypothetical example of a settlement with a population equivalent of 8970 . The settlement is located on an island in the southern Mediterranean part of Croatia. It is in a hilly area of the island and has one water reservoir located at a ground elevation of $259 \mathrm{~m}$ above sea level. Water flows into the reservoir from the wet basin of the pump station. Water flows into the wet basin of the pump station by gravity from the spring. Height difference between ground elevation of the water reservoir and water intake is $79 \mathrm{~m}$. Total head of the pump station is $82.41 \mathrm{~m}$. The water quality is satisfactory and does not need any treatment. The positions of the basic facilities of the water supply system are shown in Figure 2 (modified from [7]).

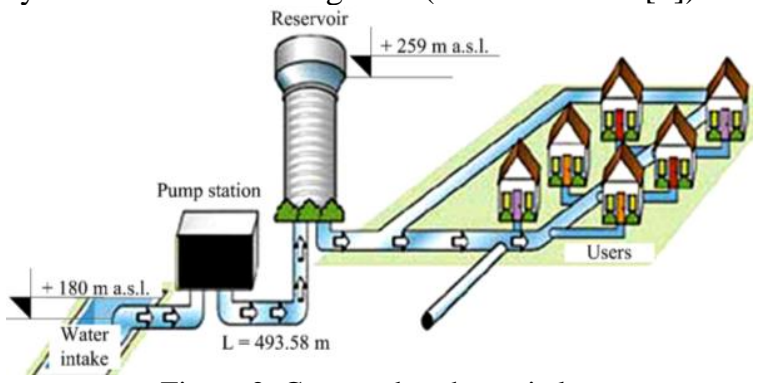

Figure 2. Case study schematic layout

The analysis is conducted according to the presented sizing methodology. Specific water consumption per capita $q_{s p}$ is 1601 per day. The daily water consumption pattern through the year is shown in Figure 3 [3]. Hourly water consumption pattern [3] in the settlement is determined by the daily regime of consumption, as shown in Figure 4.

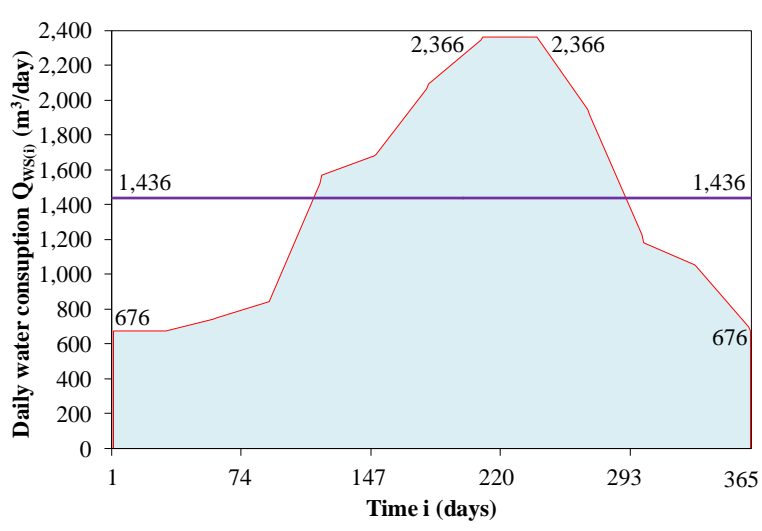

Figure 3. Daily water demand during the year

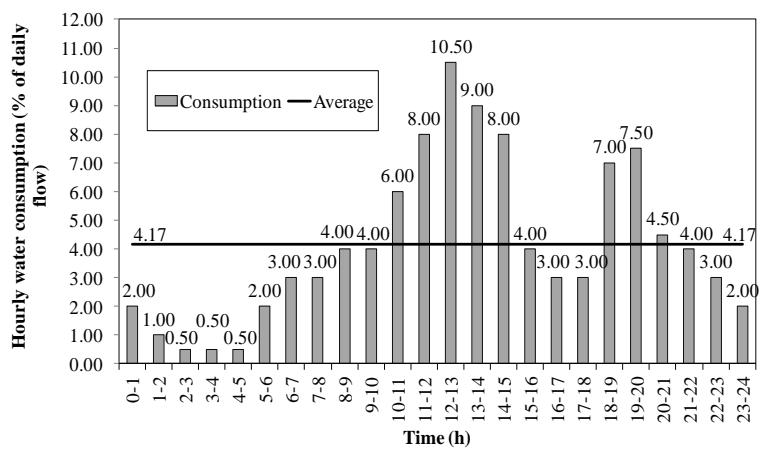

Figure 4. Hourly water demand during typical day

For the considered location, the average pump head is $H_{P S}=82.41 \mathrm{~m}$, average efficiency of the inverter and motor pump unit is $\eta_{M P I}=0.75$, cell temperature coefficient is $\alpha_{C}=0.005{ }^{\circ} \mathrm{C}^{-1}$ and temperature of the $\mathrm{PV}$ generator in Standard Test Condition is $T_{0}=25$ ${ }^{\circ} \mathrm{C}$. The average daily global radiation $E_{S(i)}$ and average daily insolation period $T_{S(i)}$ are shown in Figure 5.

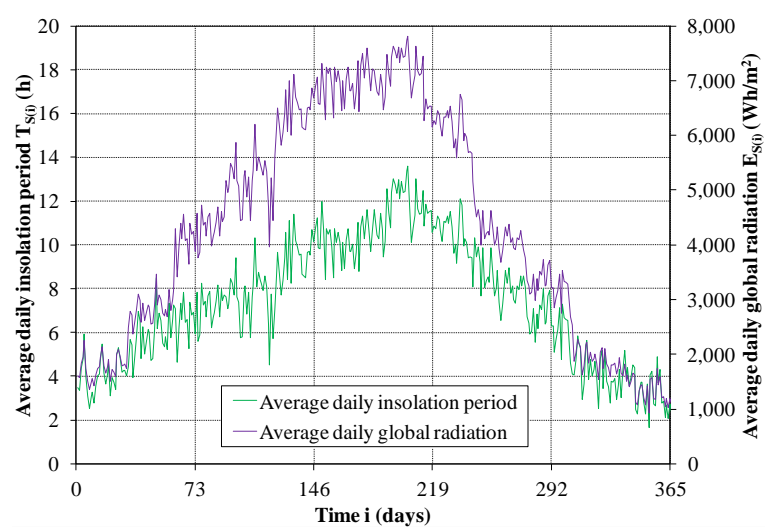

Figure 5. Average daily solar insolation values 
The average daily cell temperature $T_{\text {cell( }(i)}$ and average daily ambient air temperature $T_{a(i)}$ are shown in Figure 6 [3].

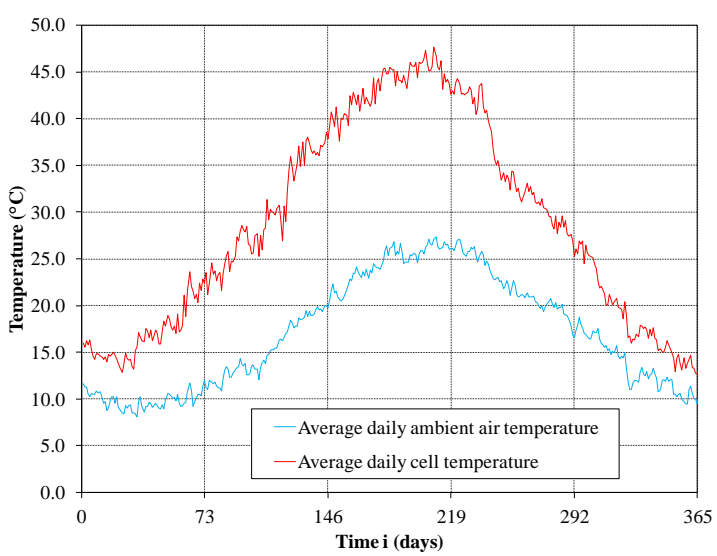

Figure 6. Average daily cell temperature and average daily ambient air temperature

\section{Results and Discussion}

Based on the given data, by applying Equations (1-3), critical periods for all subsystems have been determined (Tab. 1). Also, by applying the previously presented methodology, the required PV generator power $P_{e l, P V}^{*}$ and required reservoir volume $V_{o p}^{*}$ are calculated (Tab. 2). The required capacities of pump station $Q_{P S}^{*}$ i.e. power of pump station $P_{P S}^{*}$ are calculated by using the value of pump efficiency $\eta_{P S}=0.90$ [3].

Table 1. The length of balancing period in accordance with critical days

\begin{tabular}{|c|c|c|c|c|c|}
\hline $\begin{array}{c}\text { Balancing } \\
\text { period } \boldsymbol{t}_{\boldsymbol{b}} \text { (days) }\end{array}$ & $\mathbf{1}$ & $\mathbf{2}$ & $\mathbf{3}$ & $\mathbf{4}$ & $\mathbf{5}$ \\
\hline $\begin{array}{c}\text { Critical period } \\
\text { (days in year) for } \\
\text { subsystem PV } \\
t_{P e l(i)}^{*}\end{array}$ & 352 & $\begin{array}{c}344 \\
-\end{array}$ & $\begin{array}{c}344 \\
-\end{array}$ & $\begin{array}{c}349 \\
-\end{array}$ & $\begin{array}{c}348- \\
352\end{array}$ \\
\hline $\begin{array}{c}\text { Critical period } \\
\text { (days in year) for } \\
\text { subsystem V } \\
t_{V(i)}^{*}\end{array}$ & 244 & $\begin{array}{c}244 \\
-\end{array}$ & $\begin{array}{c}243 \\
-\end{array}$ & $\begin{array}{c}243 \\
-\end{array}$ & $\begin{array}{c}242- \\
246\end{array}$ \\
\hline $\begin{array}{c}\text { Critical period } \\
\text { (days in year) for } \\
\text { subsystem PS } \\
t_{P S(i)}^{*}\end{array}$ & 352 & - & 245 & 246 & - \\
\hline
\end{tabular}
variants 3,1,4 and 5. Variant 2 sionificantly stands out compared to the other variants, so that based on the above said, this variant is technologically the most appropriate variant. periods

\begin{tabular}{|c|c|c|c|}
\hline $\begin{array}{c}\text { Bal. } \\
\text { periods } \\
\boldsymbol{t}_{\boldsymbol{b}} \text { (days) }\end{array}$ & $\begin{array}{c}\text { Power } \\
P_{e l, P V}^{*} \\
(\mathbf{k W})\end{array}$ & $\begin{array}{c}\text { Volume } \\
V_{o p}^{*}\left(\mathbf{m}^{\mathbf{3}}\right)\end{array}$ & $\begin{array}{c}\text { Power } \\
P_{P S}^{*}(\mathbf{k W})\end{array}$ \\
\hline 1 & 512.50 & 1100 & 106.00 \\
\hline 2 & 477.82 & 1178 & 119.47 \\
\hline 3 & 443.87 & 1271 & 111.39 \\
\hline 4 & 419.80 & 1415 & 105.10 \\
\hline 5 & 403.45 & 1513 & 99.71 \\
\hline
\end{tabular}

The results obtained using the software package Promethee [8] are shown in Figure 7. All three size values of individual sub-systems, i.e. power $P_{e l, P V}^{*}$, volume $V_{o p}^{*}$ and power $P_{P S}^{*}$ have the same significance or weight. Also, maximization of all values of individual subsystems for all balancing periods was set as a necessary input condition.



Figure 7. Results obtained by using of method Promethee

It can be seen that Variant 2 is the most favorable 


\section{Conclusion}

It has been shown that the problem of selecting the technologically most appropriate variant of the water supply systems, taking into consideration a big number of criteria, can be elegantly solved by using of the multi criteria methods. In this case, the multi criteria method Promethee was applied as one of the most suitable for solving various engineering problems. In any case, further research requires more detailed and complex analysis of the problem. First of all, economic analysis should be conducted. Next step is using of other multi criteria methods, expansion of input criteria, sensitivity analysis of the change in importance/weight of individual parameters, and engaging a large number of experts from different fields in the expert group that defines and analyzes the multi-criteria analysis. Strong SWAT analysis should also support further research work.

\section{References}

[1] B. Borisov, B. Đurin and J. Matin, "The Concept of Sustainable Irrigation on the Example of Football Field of FC "Obreš"', Sveti Ilija, Croatia, Časopis Inženjerstvo okoliša, Svezak 3, Izdanje 1, pp. 71-81.

[2] J. Margeta, B. Đurin, " Multi-criteria approach in solar urban water supply systems", Proceedings of the Institution of Civil Engineers-Water Management, pp. 1-14, 2016.

[3] B. Đurin and J. Margeta, "Analysis of the Possible Use of Solar Photovoltaic Energy in Urban Water Supply Systems," Water, vol. 6, pp. 1546-1561, 2014

[4] B. Đurin, "Sustainability of the urban water supply system operating", PhD thesis (on Croatian), Faculty of Civil Engineering, Architecture and Geodesy, University of Split, Split, Croatia, 2014.

[5] J. P. Brans, Ph. Vincke and B. Mareschal, "How to select and how to rank projects: The PROMETHEE method", European Journal of Operational Research, vol. 24(2), pp. 228-238, 1986.

[6] C. Macharis, J. Springael, K. de Brucker and A. Verbeke, "PROMETHEE and AHP: The design of operational synergies in multi criteria analysis. Strengthening PROMETHEE with ideas of AHP", European Journal of Operational Research, vol. 153, pp. 307-317, 2004.

[7] District of Columbia Water and Sewer Authority About Drinking Water Quality in Washington, DC, USA. Available online: http://www.dcwater.com/drinking _water/about.cfm (accessed on 10 December 2013).
[8] Mareschal, B (2014): Manual for Visual PROMETHEE Academic Edition 1.4. See http://www.prometheegaia.net/academic-edition.html (accessed on 19/2/2014). 